\title{
Continuous Venovenous Hemodiafiltration in Patients with Multiple Organ Dysfunction Syndrome in an Intensive Care Unit
}

\author{
Anselmo A. Abdo MD MS PhD, Roberto Castellanos MD, Maykel Rocha MD, Emi Hernández MD, Geydy Leal MD, \\ Juliette Suárez MD, Juan A. Gutiérrez MD, Francisco Gómez MD, Alain Cueto MD
}

\begin{abstract}
INTRODUCTION Continuous venovenous hemodiafiltration, generally used in patients with acute renal failure, enables elimination of humoral mediators of systemic inflammatory response and sepsis from blood. This effect should improve treatment results in patients with multiple organ dysfunction, but evidence of improved survival is insufficient.
\end{abstract}

OBJECTIVES Describe the effect of continuous venovenous hemodiaflitration on patients with multiple organ dysfunction syndrome in terms of systemic and brain hemodynamics, oxygenation, metabolism and status on ICU separation.

METHODS An observational case series was done of 18 patients (11 men and 7 women) aged 24-78 years with multiple organ dysfunction syndrome treated with continuous venovenous hemodiafiltration in the Medical-Surgical Research Center's ICU in Havana. General, systemic and brain hemodynamic, oxygenation and metabolic variables were assessed immediately before and 12 hours after starting the procedure; vital status on separation from intensive care was recorded. For analysis, patients were grouped by whether cause of mul- tiple organ dysfunction syndrome was septic or nonseptic. Variable means before and after treatment were compared using the Wilcoxon matched pairs test. Standardized mortality ratios were calculated for both groups, with survival efficacy defined by a ratio of $<0.9$.

RESULTS After 12 hours continuous venovenous hemodiafitration, the septic group showed clinical improvement, with statistically significant improvement in all variables except mean arterial pressure and brain hemodynamics. Survival to discharge from ICU was $64 \%$, with a standardized mortality ratio of 0.66 . In the nonseptic group, survival was $0 \%$ and ratio was 2.13 ; temperature was the only variable found to improve significantly.

CONCLUSIONS Continuous venovenous hemodiafltration improved clinical parameters and survival in patients with multiple organ dysfunction of septic origin. Further studies are needed with larger numbers of patients to corroborate these results.

KEYWORDS Continuous renal replacement therapy, hemodiafiltration, multiple organ failure, septic shock, acute liver failure, MODS, Cuba

\section{INTRODUCTION}

Continuous renal replacement therapy (CRRT), first described in $1977,[1]$ represented a major advance in management of critically ill patients with acute renal failure (ARF). Continuous venovenous hemodiafiltration (CVVH) is a CRRT that combines two methods of clearance, diffusion (dialysis) and convection (hemofiltration), enabling extraction from blood of fluids, electrolytes and solutes with molecular weight $<50,000$ unbound to proteins. [2]

CVVH use in patients with multiple organ dysfunction (MODS) led to the discovery that not only was it useful for purging uremic toxins, electrolytes and water, but also eliminated humoral mediators of systemic inflammatory response and sepsis (interleukins 1,6 and tumor necrosis factor), mainly by convection and adsorption.[3] This suggests a potential treatment benefit in critically ill MODS patients, possibly even in those with preserved kidney function.

Despite scientific and technological advances in MODS management, case fatality remains elevated, reported by some authors between $72 \%$ and $79 \%,[4]$ and hence the need for more effective treatment.

The spectrum of sepsis, severe sepsis, septic shock and MODS represents one of the main causes of admission to and deaths in ICUs.[5-7] Thus, various groups have incorporated CVVH into treatment protocols for MODS, whether septic or nonseptic, with varying survival results. Dunham's review includes results from case series reporting use of CVVH in patients with MODS of differing etiologies with case fatality ranging between $0 \%$ and $81 \%$. [4] Most papers we reviewed reported its use in septic MODS, but there are small series or case reports describing its use in acute respiratory distress syndrome (ARDS),[8,9] acute liver failure (ALF) [10] and pancreatitis,[11] all conditions associated with high mortality and in which physiopathologic inflammatory response mediators are implicated. Indications for CVVH use in this last group is more controversial than in septic MODS patients.[8-11]

A Cochrane meta-analysis in 2007 showed an advantage of CRRT over intermittent therapy in patients with ARF in variables that reflect hemodynamic instability (hypotension, mean arterial blood pressure and need for vasopressor drugs), but there was not enough evidence of ultimate improvement in survival.[12] A large multicenter trial comparing intermittent hemodialysis with CVVH in ARF patients found no difference in 60-day survival. [13] Since CVVH is costly, research to demonstrate a survival benefit is needed to support any routine use in MODS treatment.

Use of extracorporeal technology to support critically ill patients with organic dysfunction is a research line of the ICU at the Medical-Surgical Research Center (CIMEQ, the Spanish acronym) in Havana. Our literature found no studies assessing the usefulness of CVVH in improving MODS patient survival in Cuban ICUs. The objective of this study was to describe the effect of CVVH on systemic and brain hemodynamics, oxygenation and metabolism, as well as on vital status at separation of a group of MODS patients treated in CIMEQ's ICU.

\section{METHODS}

Definitions MOD: Disturbance in two or more systems for at least 24 hours in a critically ill patient unable to maintain homeostasis without intervention.[14] 
ARF: Acute increase in plasma creatinine concentration more than twice baseline value or reduction of glomerular filtration rate by $>50 \%$ or urinary excretion $<0.5 \mathrm{~mL} / \mathrm{kg} / \mathrm{h}$ for 6 hours.[15]

ALF: Severe liver dysfunction with acute onset in absence of preexisting liver disease, characterized by liver encephalopathy and coagulopathy.[16]

ARDS: Acute respiratory failure independent of cause, according to American-European consensus criteria: acute onset, arterial oxygen tension $\left(\mathrm{PaO}_{2} / \mathrm{FiO}_{2}\right.$ ratio $) \leq 200 \mathrm{mmHg}$, diffuse bilateral infiltrates in the anterior-posterior chest $\mathrm{X}$-ray and lung capillary pressure $<18 \mathrm{mmHg}$, when measured, or without clinical evidence of cardiac failure.[17]

Study type and population An observational case series study was conducted of 18 patients hospitalized in CIMEQ's ICU between 2007 and 2010 who received CVVH for MODS, either as admitting diagnosis or developed during hospitalization. Seven were women $(38.9 \%)$ and 11 men $(61.1 \%)$, aged 24 to 78 years (median 49.3, SD \pm 15.9 ). Mean APACHE II[18] score immediately pre-CVVH was 24.5 (range 7 to $38, S D \pm 8.24$ ) and death risk was $51.9 \%$ (range $7.6 \%$ to $88.4 \%$, SD $\pm 24.24 \%$ ). MODS was caused by sepsis in $11(61.1 \%)$ patients, ALF in $4(22.2 \%)$, ARDS in $2(11.1 \%)$ and ARF in $1(5.6 \%)$.

Inclusion criteria Patients with MODS of any etiology who received $\mathrm{CVVH}$ for more than 12 hours.

Ethical considerations The study was approved by the CIMEQ ethics committee. Patients or relatives (of patients with impaired consciousness or who were sedated) provided written informed consent following explanation of the study's objectives, risks and benefits.

Study variables General data collected for each patient included age, sex, cause of MODS, pre-CVVH APACHE II score, death risk and system dysfunction per the Sequential Organ Failure Assessment[19] without the neurological component (Table 1). Systemic hemodynamic variables were heart rate; mean arterial pressure (MAP) recorded by invasive monitoring through the radial artery using a Nihon Kodhen (Japan) monitor; and norepinephrine dose. Brain hemodynamic variables were right middle cerebral artery mean flow velocity (MCA MFV) and pulsatility index (MCA PI), collected by transcranial Doppler sonography through the temporal window, using Multi-Dop-T, DWL (Germany).[22] Oxygenation variables were arterial oxygen saturation $\left(\mathrm{SaO}_{2}\right.$, recorded by pulsioximMCA: Middle cerebral artery $\mathrm{PI}$ : Pulsatility index eter using Nihon Kodhen monitor, Japan) and inspired oxygen fraction $\left(\mathrm{FiO}_{2}\right)$. Metabolic variables were body temperature and serum creatinine, urea and bicarbonate concentrations (creatinine and urea measured in serum by Automatic Analyzer 912 Hitachi, Japan; bicarbonate measured in arterial blood using a gasometer ABL 700 Series, Radiometer, Denmark). Systemic, cerebral, oxygenation and metabolic hemodynamic variables were measured both immediately before CVVH and 12 hours after its onset. Furthermore, the hemofiltration dose used at 12 hours from procedure onset was recorded. Final results evaluated were vital status at separation from ICU and standardized mortality ratio (SMR).

CVVH technique A Prismaflex (Gambro-Hospal, Sweden) monitor was used. Dialisan B2GD (Gambro-Hospal, Sweden) was
Table 1: Study variables

\begin{tabular}{l|l}
\hline Variable & \multicolumn{1}{c}{ Description } \\
\hline General & \\
\hline Age (years) & Continuous variable \\
Sex & Male, female \\
\hline MODS cause & Septic, nonseptic \\
\hline APACHE II & $\begin{array}{l}\text { Disease severity scale including } 12 \text { physiological variables, } \\
\text { age and prior health status, used to predict risk of death } \\
\text { low risk: }<20 \text { points } \\
\text { high risk: } 20-30 \text { points } \\
\text { very high risk: }>30 \text { points[18] }\end{array}$ \\
\hline Death risk (expected) & $\begin{array}{l}\text { Prediction model from APACHE II score: } \\
\text { logistic regression formula }=\text { In }(\mathrm{R} / 1-\mathrm{R})-3.517=(\mathrm{APACHE} \\
\text { II score } \mathrm{x} 0.146)+0.603 \text { only if emergency surgery }+ \text { diag- } \\
\text { nostic category coefficient[18] }\end{array}$
\end{tabular}

Organ system dysfunction/failure Per Sequential Organ Failure Assessment (SOFA): scoring system to assess morbidity and degree of dysfunction of every organ[19]

\begin{tabular}{|c|c|}
\hline Hemodiafiltration dose $(\mathrm{mL} / \mathrm{kg} / \mathrm{h})$ & $\begin{array}{l}\text { [Effluent }(\mathrm{mL} / \mathrm{h})] / \text { weight in } \mathrm{kg} \\
\text { recommended septic MODS dose: } 35 \mathrm{~mL} / \mathrm{kg} / \mathrm{h}[20]\end{array}$ \\
\hline \multicolumn{2}{|l|}{ Systemic hemodynamics } \\
\hline HR (beats/min) & Normal range: $60-100$ (beats/min)[21] \\
\hline MAP $(\mathrm{mmHg})$ & $\begin{array}{l}\text { [Systolic arterial pressure }+2 \text { (diastolic arterial pressure)]/3. } \\
\text { Normal range: } 70-105 \mathrm{mmHg}[21]\end{array}$ \\
\hline Norepinephrine $(\mu \mathrm{g} / \mathrm{kg} / \mathrm{min})$ & Dose: $0.05-1.0 \mu \mathrm{g} / \mathrm{kg} / \mathrm{min}[21]$ \\
\hline \multicolumn{2}{|l|}{ Brain hemodynamics } \\
\hline Right MCA MFV (cm/s) & Normal range: $46-86 \mathrm{~cm} / \mathrm{seg}[22]$ \\
\hline Right MCA PI & Normal range: $>0.6-1.1[22]$ \\
\hline \multicolumn{2}{|l|}{ Oxygenation } \\
\hline $\mathrm{SaO}_{2}(\%)$ & Normal value: $95-100 \%[21]$ \\
\hline $\mathrm{FiO}_{2}(\%)$ & $\begin{array}{l}\text { Inspired oxygen fraction in inspired air: } \\
\text { Normal in environmental air, } 21 \% \\
\text { With mechanical ventilation, harmful if }>50 \%[21]\end{array}$ \\
\hline \multicolumn{2}{|l|}{ Metabolic } \\
\hline Creatinine $(\mu \mathrm{mol} / \mathrm{L})$ & Normal range: $53-115 \mu \mathrm{mol} / \mathrm{L}[21]$ \\
\hline Urea (mmol/L) & Normal range: $2.9-7.5 \mathrm{mmol} / \mathrm{L}[21]$ \\
\hline Bicarbonate (meq/L) & Normal range: $22-26$ mEq/L[21] \\
\hline Temperature $\left({ }^{\circ} \mathrm{C}\right)$ & Normal range: $36.5-37.2^{\circ} \mathrm{C}[21]$ \\
\hline Result & \\
\hline
\end{tabular}

Vital status at separation from ICU Alive or deceased

SMR Observed/expected deaths[23]

$\mathrm{FiO}_{2}$ : Inspired oxygen fraction
HR: Heart rate $\mathrm{SaO}_{2}$ : Arterial oxygen saturation SMR: Standardized mortality ratio 
the dialysis fluid with a sodium bicarbonate buffer. Replacement solution was Hemosol B0 (Gambro-Hospal, Sweden) and the mean hemofiltration dose was $31.22 \mathrm{~mL} / \mathrm{kg} / \mathrm{h}$ (limits $17-50 \mathrm{~mL}$ / $\mathrm{kg} / \mathrm{h}$, SD: \pm 7.125 ). The filter used was M100 (AN69) (GambroHospal, Sweden) with biocompatible polyacrylonitrile membrane of $0.9 \mathrm{~m}^{2}$ surface. Initial blood flow was $100 \mathrm{~mL} / \mathrm{h}$ and dialysis fluid was programmed at $1000 \mathrm{~mL} / \mathrm{h}$; the substitution fluid, 1000 $\mathrm{mL} / \mathrm{h}$, and replacement through a predilution blood pump at 500 $\mathrm{mL} / \mathrm{h}$. Later, depending on clinical course and laboratory monitoring, modifications were made to blood flow (up to $250 \mathrm{~mL} / \mathrm{min}$ ) and replacement through the predilution blood pump (up to 1000 $\mathrm{mL} / \mathrm{h}$ ). System anticoagulation was applied with sodium heparin at an initial dose of $5-10 \mathrm{lU} / \mathrm{kg} / \mathrm{h}$, adjusted to maintain partial prothromboplastin time between 60 and 80 seconds. Venous access was via double lumen catheter $(13 \mathrm{~F})$ in the femoral, jugular or subclavian veins. Average duration of $\mathrm{CVVH}$ was 3.4 days.

Data collection and analysis A data collection model specifically designed for the study was used and a database created using SPSS 13.0. Patients were assigned to two groups by cause of MODS for purposes of analysis: septic and nonseptic.

A summary of pre-CVVH patient characteristics in both groups and hemodiafiltration dose after 12 hours of $\mathrm{CVVH}$ is provided in Table 2.

Table 2: Patient characteristics* by MODS cause

\begin{tabular}{|c|c|c|}
\hline Variable & $\begin{array}{l}\text { Septic } \\
(n=11)\end{array}$ & $\begin{array}{l}\text { Nonseptic } \\
(n=7)\end{array}$ \\
\hline Age (years) $(X \pm S D)$ & $53.7 \pm 16.3$ years & $42.3 \pm 13.2$ years \\
\hline APACHE II (X \pm SD) & $25.6 \pm 7.8$ & $22.7 \pm 9.3$ \\
\hline Death risk $(\%)(X \pm S D)$ & $55.0 \pm 23.8$ & $47.0 \pm 25.9$ \\
\hline Cardiovascular D/F & $90.9 \%(10)$ & $71.4 \%(5)$ \\
\hline Kidney D/F & $81.8 \%(9)$ & $71.4 \%(5)$ \\
\hline Liver D/F & $72.7 \%(8)$ & $85.7 \%(6)$ \\
\hline Respiratory D/F & $63.6 \%(7)$ & $85.7 \%(6)$ \\
\hline Coagulatory D/F & $63.6 \%(7)$ & $85.7 \%(6)$ \\
\hline $\begin{array}{l}\text { Final hemodiafiltration } \\
\text { dose }(X \pm D E)\end{array}$ & $31.45 \pm 3.1 \mathrm{~mL} / \mathrm{kg} / \mathrm{h}$ & $30.86 \pm 11.3 \mathrm{~mL} / \mathrm{kg} / \mathrm{h}$ \\
\hline
\end{tabular}

Analysis was performed separately for each group. Means and standard deviations were used to describe quantitative values and percentages for qualitative ones. The Wilcoxon matched pairs test was used to compare pre- and 12-hour post-CVVH means for systemic and brain hemodynamic, oxygenation and metabolic variables. This period was chosen since it allows sufficient time for the procedure to have an effect and to help reduce confounding by applying homogenous timing in a heterogeneous group of patients. Statistical significance was defined by $p$ value of $<0.05$. Predicted and observed outcomes were compared for each diagnostic group using SMR.

Treatment effect System hemodynamic efficacy was determined by return to normal values in heart rate, mean arterial pressure and reduced need for norepinephrine. Brain hemodynamic efficacy was defined by return to normal values of right MCA MFV and right MCA PI. Metabolic efficacy was defined as return to normal levels of serum creatinine, urea and bicarbonate. Survival efficacy was defined by an SMR of $<0.9$.

\section{RESULTS}

Dysfunctional systems in the entire series were, in order of frequency: cardiovascular, 83.3\% (15/18); renal and hepatic, each $77.8 \%$ (14/18); and respiratory and coagulatory, each $72.2 \%$ $(13 / 18)$. The percentage of system dysfunction by diagnostic group is shown in Table 2.

Comparing clinical and laboratory values pre-CVVH and at 12 hours after initiation, statistically significant improvement was observed in the septic group (Table 3) in all except for mean arterial pressure and right MCA MFV and right MCA PI. However, in the nonseptic group, only temperature showed significant improvement (Table 3).

Relating final outcome (alive or dead) at ICU discharge and diagnostic groups (sepsis vs. non sepsis): 7 of the 11 patients in the septic MODS group were discharged alive from ICU, representing $63.7 \%$ survival (SMR 0.66). None of the nonseptic MODS patients survived (SMR 2.13) (Table 4).

\section{DISCUSSION}

This case series, similar to others reported,[24-26] comprised critically ill patients at high risk of death because of the severe organ disturbances that characterize MODS. In the case series we reviewed, the major failing systems were consistent with ours, with cardiovascular (94-100\%) and renal $(100 \%)$ systems predominant.[24,25] Our series included four patients without ARF treated with $\mathrm{CVVH}$ for septic-origin MODS who were discharged alive from ICU; studies with a larger number of cases would be useful to define CVVH indications in MODS patients of septic origin without ARF, as suggested by other authors, because of the procedure's elimination of humoral mediators of systemic inflammatory response and sepsis.[2,3]

Sepsis was the predominant cause of MODS in our series and constituted the principal or sole diagnosis in the majority of reports reviewed for comparison.[4,25-27] Among nonseptic causes in our series, the most frequent was ALF, since CIMEQ has one of the two liver transplant programs in Cuba and our ICU receives liver failure patients from every hospital in the country. As in the case of septic MODS, the high mortality risk associated with nonseptic MODS compels us to search for more effective treatments, which is why these cases were included here. The literature describing use of CVVH in ALF and ARDS consists solely of case reports or small case series such as ours. $[8,9,28,29]$

In our septic MODS patients, there was a statistically significant improvement in all but three variables studied. Such improvement in systemic hemodynamics, oxygenation and metabolism variables with CVVH in patients with septic MODS has been reported by other authors, $[25,27]$ and may be explained by the purifying effect of dialysis, eliminating urea and creatinine through the filter membrane, which stabilizes the internal environment. Removal of inflammatory response mediators and fluid by hemofiltration and adsorption can also explain improvement in systemic hemodynamics and oxygenation in patients with poor fluid balance. $[2,25,27]$

In the group of patients with nonseptic MODS, even though variables (excluding temperature) showed no significant improve- 
Table 3: Systemic and brain hemodynamics, oxygenation and metabolic variables pre-CVVH and at 12 hours after CVVH start, by MODS causation

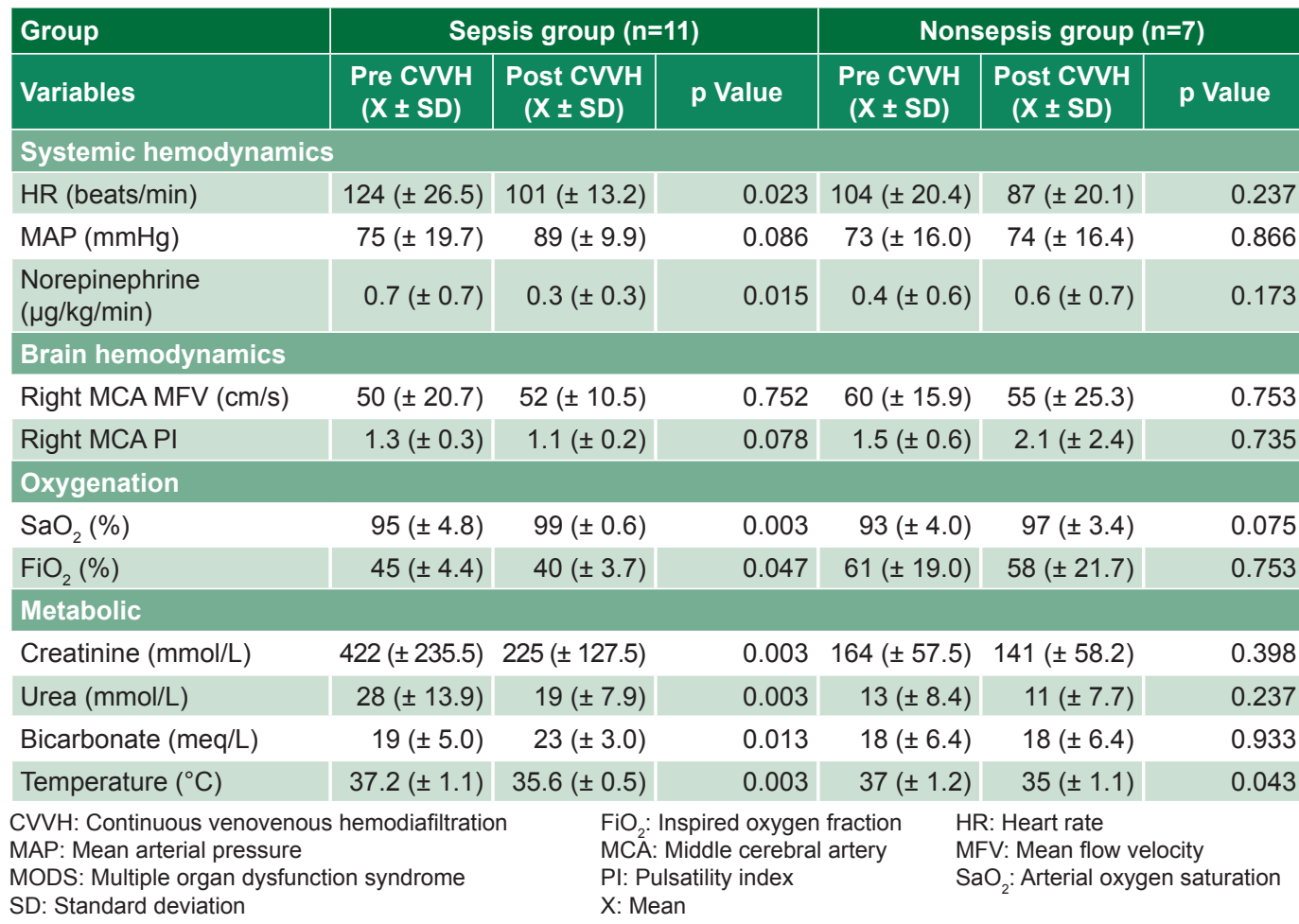

Table 4: Prognostic values at CVVH start (APACHE II, predicted death risk) and final result (\% deceased, SMR), by MODS causation

\begin{tabular}{|l|r|r|r|r|}
\hline MODS causation & $\begin{array}{c}\text { APACHE II } \\
(\mathbf{X} \pm \text { SD) }\end{array}$ & $\begin{array}{c}\text { Predicted death risk (\%) } \\
(\mathbf{X} \pm \text { SD) }\end{array}$ & $\begin{array}{c}\text { \% Deceased } \\
(\mathbf{n})\end{array}$ & SMR \\
\hline Septic $(n=11)$ & $25.6( \pm 7.8)$ & $55.0( \pm 23.8)$ & $36.4(4)$ & 0.66 \\
\hline Nonseptic $(n=7)$ & $22.7( \pm 9.3)$ & $47.0( \pm 25.9)$ & $100.0(7)$ & 2.13 \\
\hline
\end{tabular}

X: Mean SD: Standard deviation SMR: Standardized mortality ratio

ment, there was some improvement in metabolic and oxygenation variables; the lack of statistical significance may have been due to small sample size and hence limited study power.

However, this group's results are interesting, even though they did not benefit as did the septic MODS patients, taking their diagnosis into account. In the case of patients with ALF, for whom the ultimate solution is liver transplantation, the therapeutic objective would be to improve or stabilize multiple organ function to 'buy time' while awaiting a donor organ, to improve the patient's condition for transplantation or assist in stabilizing the patient post transplantation.[29]

Impairment of brain hemodynamic variables-although without statistical significance-may be explained in patients with ALF, in whom worsening encephalopathy is characterized by greater brain edema and progressive deterioration of these parameters, as previously reported.[30] Although not found to be significant in this study, improving oxygenation and metabolic variables could be useful in treating patients with ARDS, ALF and MODS, as shown by Matsuda.[31]

The decrease in temperature to as low as $35^{\circ} \mathrm{C}$ could be useful in view of studies suggesting possible benefits of moderate hypo- thermia $\left(32-35^{\circ} \mathrm{C}\right)$ in ALF and ARDS.[32,33] The mechanism invoked in ALF patients is lessened brain edema and intracranial hypertension because of reduced production of splanchnic ammonium, restoration of brain hemodynamic regulation and reduction in brain oxidative metabolism.[34] In ARDS animal models, moderate hypothermia inhibits adhesion, activation and accumulation of neutrophils during the acute phase.[33]

Apart from observed improvements in oxygenation and metabolic hemodynamic variables, the high rate of survival to ICU discharge of septic MODS patients with $\mathrm{CVVH}$ is noteworthy because lack of evidence for a survival benefit is one of the criticisms of this procedure. $[2,4,35,36]$

SMR calculated for the septic MODS group by comparing expected mortality per APACHE II values to observed mortality was similar to the SMR of 0.67 reported by Page for septic MODS patients, with 53\% mortality.[25] This must be considered treatment efficacy. As previously discussed, nonseptic MODS patients did not derive this benefit.
The study's main limitations are its small size and lack of control group, so results must be considered preliminary. In addition, numbers were too small to permit analysis by subgroups using SOFA scores, and the hemodiafiltration dose used was lower than currently recommended for septic patients. Despite these limitations and because of encouraging survival observed in the sepsis group, we view CVVH as a promising intervention that should be considered for septic MODS, which despite medical progress still has high case fatality rates.

Multicenter studies will be needed with increased sample size to better assess these new technologies, which, while costly, could yield satisfactory cost-effectiveness for survival in these patients. New studies on the topic should include confounders, such as time elapsed between symptom onset and procedure initiation, inter alia.

\section{CONCLUSIONS}

Continuous venovenous hemodiafltration improved clinical parameters and survival in patients with multiple organ dysfunction syndrome of septic origin. Further studies are warranted with larger numbers of patients to corroborate these results for the sake of improving treatment of such critically ill patients. - p 


\section{REFERENCES}

1. Kramer P, Wigger W, Rieger J, Matthaei D, Scheler F. [Arteriovenous hemofiltration: $A$ new and simple method for treatment of overhydratated patients resistant to diuretics]. Klin Wochenschr. 1977 Nov 15;55(22):1121-2. German.

2. Blankestijn PJ, Ledebo I, Canaud B. Hemodiafiltration: clinical evidence and remaining questions. Kidney Int. 2010 Apr;77(7):581-7.

3. Saito A. Current progress in blood purification methods used in critical care medicine. Contrib Nephrol. 2010;166:100-11.

4. Dunham CM. Clinical impact of continuous renal replacement therapy on multiple organ failure. World J Surg. 2001 May;25(5):669-76.

5. O`Brien JM Jr, Lu B, Ali NA, Levine DA, Aberegg SK, Lemeshow $S$. Insurance type and sepsisassociated hospitalizations and sepsis-associated mortality among US adults: a retrospective cohort study. Crit Care. 2011;15(3):R130.

6. Vincent JL, Nelson DR, Williams MD. Is worsening multiple organ failure the cause of death in patients with severe sepsis? Crit Care Med. 2011 May;39(5):1050-5.

7. Gustot T. Multiple organ failure in sepsis: prognosis and role of systemic inflammatory response. Curr Opin Crit Care. 2011 Apr;17(2):153-9.

8. Cosentino F, Paganini E, Lockrem J, Stoller $\mathrm{J}$, Wiedemann $\mathrm{H}$. Continuous arteriovenous hemofiltration in the adult respiratory distress syndrome: a randomized trial. Contrib. Nephrol. 1991:93:94-7.

9. Garzia F, Todor R, Scalea T. Continuous arteriovenous hemofiltration countercurrent dialysis (CAVH-D) in acute respiratory failure (ARDS). J Trauma. 1991 Sep;31(9):1277-84.

10. Inoue $\mathrm{K}$, Watanabe T, Maruoka N, Kuroki Y, Takahashi H, Yoshiba M. Japanese-style intensive medical care improves prognosis for acute liver failure and the perioperative management of liver transplantation. Transplant Proc. 2010 Dec;42(10):4109-12.

11. Blinzler L, Hausser J, Bödeker $H$, Zaune $U$, Martin E, Gebhardt C. Conservative treatment of severe necrotizing pancreatitis using early continuous venovenous hemofiltration. Contrib Nephrol. 1991;93:234-6.

12. Rabindranath K, Adams J, Macleod AM, Muirhead N. Intermittent versus continuous renal replacement therapy for acute renal failure in adults. Cochrane Database Syst Rev. 2007 Jul 18;(3):CD003773.

13. Vinsonneau C, Camus C, Combes A, Costa de Beauregard MA, Klouche K, Boulain T, et al. Hemodiafe Study Group. Continuous venovenous haemodiafiltration versus intermittent haemodialysis for acute renal failure in patients with multiple-organ dysfunction syndrome: a multicentre randomised trial. Lancet. $2006 \mathrm{Jul}$ 29;368(9533):379-85.

14. American College of Chest Physicians/Society of Critical Care Medicine Consensus Conference: definitions for sepsis and organ failure and guidelines for the use of innovative therapies in sepsis. Crit Care Med. 1992 Jun;20(6):864-74.

15. Bagshaw SM, George C, Dinu I, Bellomo R. A multi-centre evaluation of the RIFLE criteria for early acute kidney injury in critically ill patients. Nephrol Dial Transplant. 2008 Apr;23(4):1203-10.

16. Sundaram V, Shaikh OS. Acute liver failure: current practice and recent advances. Gastroenterol Clin North Am. 2011 Sep;40(3):523-39.

17. Villar J, Blanco J, Kacmarek RM. Acute respiratory distress syndrome definition: do we need a change? Curr Opin Crit Care. 2011 Feb;17(1):13-7.

18. Knaus WA, Draper EA, Wagner DP, Zimmerman JE. APACHE II: a severity of disease classification system. Crit Care Med. 1985 Oct;13(10):818-29.

19. Vincent JL, Moreno R, Takala J, Willatts S, De Mendonça A, Bruining $\mathrm{H}$, et al. The SOFA (Sepsis-related Organ Failure Assessment) score to describe organ dysfunction/failure. On behalf of the Working Group on Sepsis-Related Problems of the European Society of Intensive Care Medicine. Intensive Care Med. 1996 Jul;22(7):707-10.

20. Honore PM, Jacobs R, Joannes-Boyau O, De Regt J, Boer W, De Waele E, et al. Septic AKI in ICU patients. Diagnosis, pathophysiology, and treatment type, dosing, and timing: a comprehensive review of recent and future developments. Ann Intensive Care. 2011 Aug 9;1(1):32.

21. McGee WT, Headley JM, editors. Quick Guide to Cardiopulmonary Care [Internet]. 2nd ed. California: Edwards Lifesciences; [date unknown] [cited 2012 Mar 30]. Available from: http://ht.edwards .com/sci/edwards/sitecollectionimages/products/ mininvasive/ewquickguide2ed.pdf

22. White $\mathrm{H}$, Venkatesh B. Applications of transcranial Doppler in the ICU: a review. Intensive Care Med. 2006 Jul;32(7):981-94.

23. Abizanda R, Reig R, FerrándizA, Mas S. El cuadro de mando de la gestión clínica en Medicina Intensiva [Internet]. REMI. 2009 Apr [cited: 2011 Feb 20];9(4):A99. Available from: http://remi.uninet. edu/2009/04/REMIA099i.html. Spanish.

24. Sirvent JM, Vallés M, Navas E, Calabia J, Ortiz $\mathrm{P}$, Bonet $\mathrm{A}$. [Outcome of critically ill patients with acute renal failure and multiple organ failure treated with continuous venovenous haemodiafiltration]. Med Intensiva. 2010 Mar;34(2):95-101. Spanish.

25. Page B, Vieillard-Baron A, Chergui K, Peyrouset O, Rabiller A, Beauchet A, et al. Early venovenous haemodiafiltration for sepsis-related multiple organ failure. Crit Care. 2005;9(6):R755-63.

26. Honore PM, Jamez J, Wauthier M, Lee PA, Dugernier T, Pirenne B, et al. Prospective evaluation of short-term, high-volume isovolemic hemofiltration on the hemodynamic course and outcome in patients with intractable circulatory failure resulting from septic shock. Crit Care Med. 2000 Nov;28(11):3581-7.

27. Nakada TA, Oda S, Matsuda K, Sadahiro $T$, Nakamura M, Abe R, et al. Continuous hemodiafiltration with PMMA Hemofilter in the treatment of patients with septic shock. Mol Med. 2008 May-Jun;14(5-6):257-63.

28. Arata S, Tanaka K, Takayama K, Moriwaki Y, Suzuki N, Sugiyama M, et al. Treatment of hepatic encephalopathy by on-line hemodiafiltration: a case series study. BMC Emerg Med. 2010 May 21;10:10.

29. Yokoi T, Oda S, Shiga H, Matsuda K, Sadahiro T, Nakamura M, et al. Efficacy of high-flow dialysate continuous hemodiafiltration in the treatment of fulminant hepatic failure. Transfus Apher Sci. 2009 Feb;40(1):61-70.

30. Abdo A, López O, Fernández A, Santos J, Castillo J, Castellanos R, et al. Transcranial Doppler sonography in fulminant hepatic failure. Transplant Proc. 2003 Aug;35(5):1859-60.

31. Matsuda K, Moriguchi T, Oda S, Hirasawa H. Efficacy of continuous hemodiafiltration with a cytokine-adsorbing hemofilter in the treatment of acute respiratory distress syndrome. Contrib Nephrol. 2010;166:83-92.

32. Dmello D, Cruz-Flores S, Matuschak GM. Moderate hypothermia with intracranial pressure monitoring as a therapeutic paradigm for the management of acute liver failure: a systematic review. Intensive Care Med. 2010 Feb;36(2):210-3.

33. Kira S, Daa T, Kashima K, Mori M, Noguchi T, Yokoyama S. Mild hypothermia reduces expression of intercellular adhesion molecule1 (ICAM-1) and the accumulation of neutrophils after acid-induced lung injury in the rat. Acta Anaesthesiol Scand. 2005 Mar;49(3):351-9.

34. Stravitz RT, Larsen FS. Therapeutic hypothermia for acute liver failure. Crit Care Med. 2009 Jul;37(7 Suppl):S258-64.

35. Soni SS, Nagarik AP, Adikey GK, Raman A Using continuous renal replacement therapy to manage patients of shock and acute renal failure. J Emerg Trauma Shock. 2009 Jan;2(1):19-22.

36. den Hoedt $\mathrm{CH}$, Mazairac $\mathrm{AH}$, van den Dorpel MA, Grooteman MP, Blankestijn PJ. Effect of hemodiafiltration on mortality, inflammation and quality of life. Contrib Nephrol. 2011;168:39-52.

\section{THE AUTHORS}

Anselmo A. Abdo Cuza (Corresponding author: aaabdo@infomed.sld.cu), intensive care and emergency medicine specialist. Full professor, Medical University of Havana, and chief of ICU, Medical-Surgical Research Center (CIMEQ), Havana, Cuba.

Roberto Castellanos Gutiérrez, intensive care and emergency medicine specialist, CIMEQ ICU, and ssociate professor, Medical University of Havana, Cuba.

Maykel Rocha Quintana, intensive care and emergency medicine specialist, CIMEQ ICU, and instructor, Medical University of Havana, Cuba.

Emi Hernández Fernández, intensive care and emergency medicine specialist, CIMEQ ICU, Havana, Cuba.

Geydy Leal Alpízar, intensive care and emergency medicine specialist, CIMEQ ICU, Havana, Cuba.

Juliette Suárez López, anesthesiologist. Hermanos Ameijeiras Clinical-Surgical Teaching Hospital ICU and instructor, Medical University of Havana, Cuba.

Juan Antonio Gutiérrez Martínez, intensive care and emergency medicine specialist, CIMEQ ICU, and instructor, Medical University of Havana, Cuba.

Francisco Gómez Peire, intensive care and emergency medicine specialist, CIMEQ ICU, and instructor, Medical University of Havana, Cuba.

Alain Cueto Medina, intensive care and emergency medicine specialist, CIMEQ ICU, and associate professor, Medical University of Havana, Cuba.

Submitted: August 10, 2011

Approved: July 18, 2012

Disclosures: None 